\title{
ERRATUM
}

\section{Erratum to: Floral Preference of Melipona eburnea Friese (Hymenoptera: Apidae) in a Colombian Andean Region}

\author{
D Obregon ${ }^{1,2}$, G Nates-Parra ${ }^{2}$ \\ ${ }^{1}$ Universidad de la Salle, Yopal, Casanare, Colombia \\ ${ }^{2}$ Depto de Biología, Univ Nacional de Colombia, Lab de Investigaciones en Abejas (LABUN), Bogotá, Cundinamarca, Colombia
}

\section{Erratum to: Neotrop Entomol DOI 10.1007/s13744-013-0172-y}

Due to an unfortunate turn of events, the individual images were incorrectly identified in the caption of Fig 1 . The correct image and its caption is published on the next page and should be treated as definitive by the reader. 

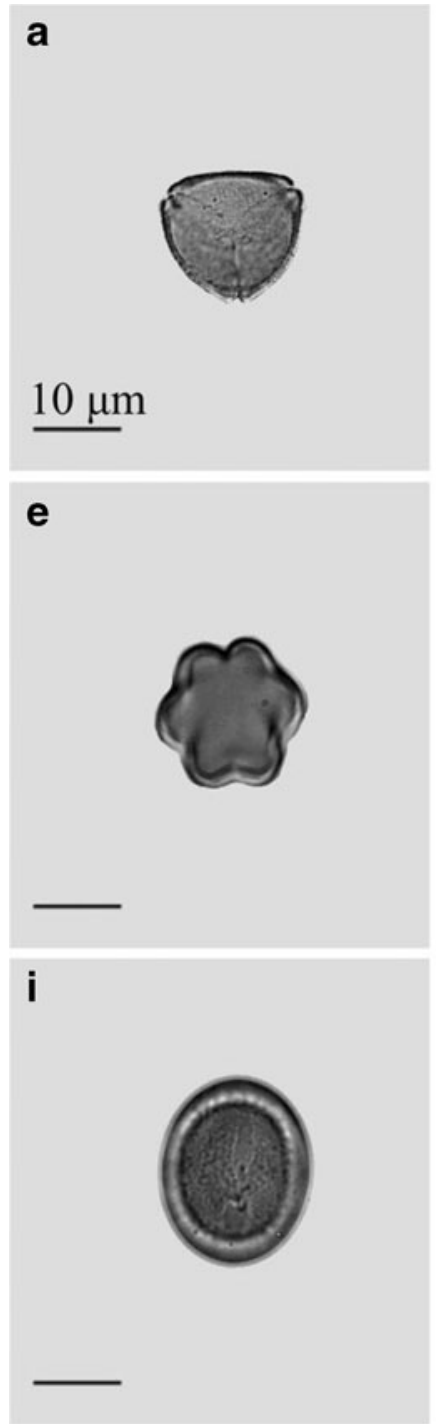

m

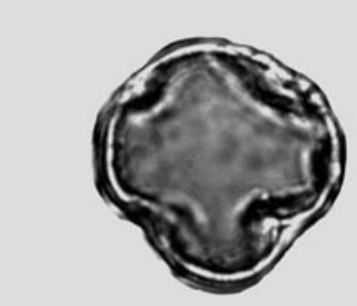

b
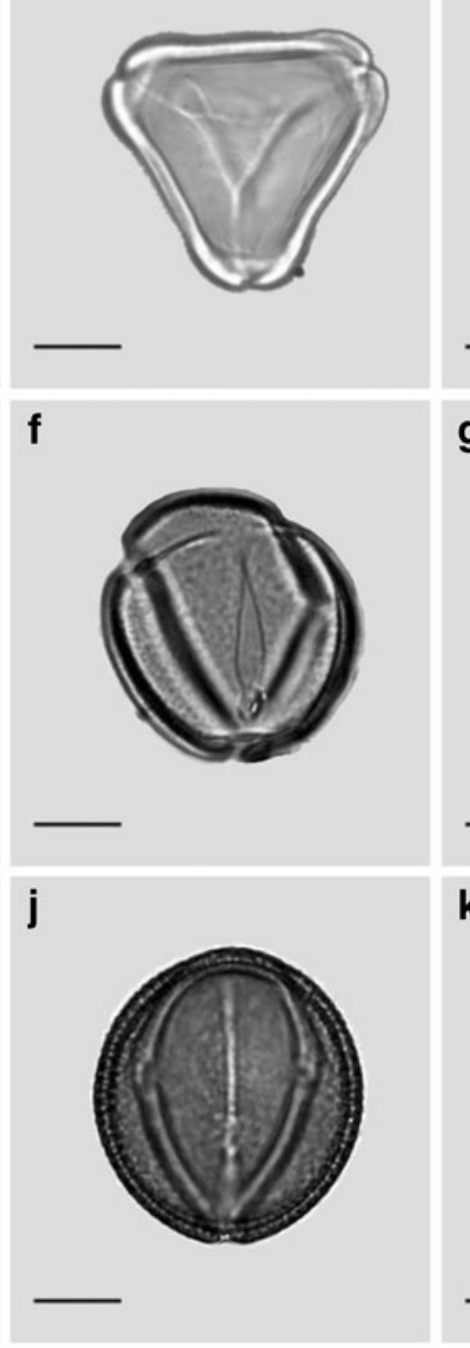

n

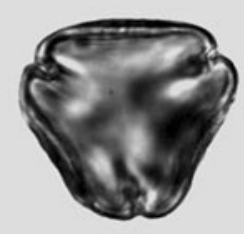

c

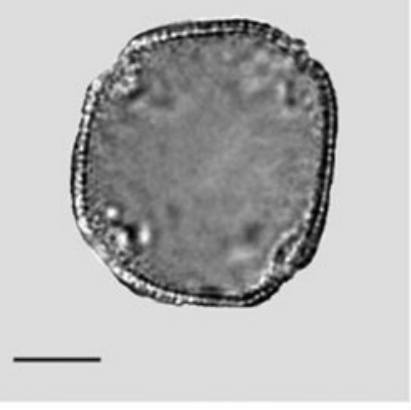

g

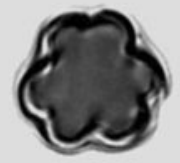

k

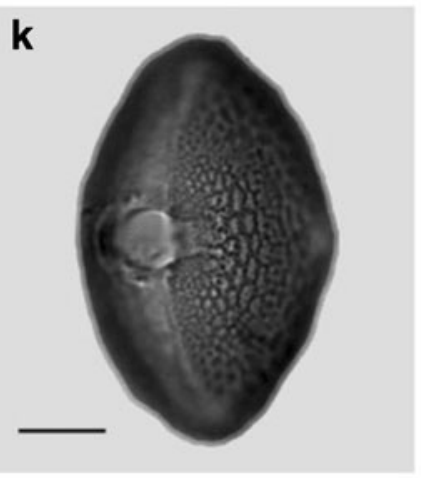

0

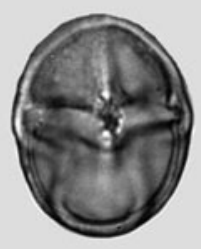

d

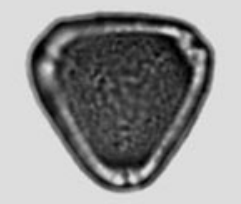

h

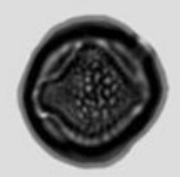

I

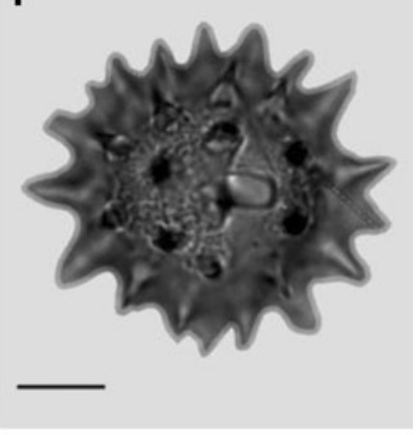

p

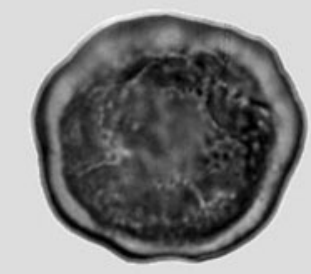

Fig 1 a Myrcia type; b Eucalyptus globulus; c Fraxinus uhdei; d Psidium guajava; e Tibouchina longifolia; $\mathbf{f}$ Cassia grandis; $\mathbf{g}$ Miconia type; $\mathbf{h}$ Muntingia calabura; i Adenaria floribunda; $\mathbf{j}$ Antigonon leptopus; k Heliocarpus americanus; I Steiractinia aspera; $\mathbf{m}$ Myrsine coriaceae; $\mathbf{n}$ Vitis tiliifolia; o Solanum aturense; p Saurauia scabra. 